\title{
Duas décadas de consolidação da paz: as críticas ao modelo das Nações Unidas*
}

\section{Two decades of peacebuilding: the United Nations model and its critics}

Teresa Almeida Cravo'

\footnotetext{
Recebido em 23/09/2013.

Aprovado em 08/10/2013.

Este texto foi escrito com as regras ortográficas vigentes em Portugal.

1 Professora Auxiliar de Relações Internacionais e Investigadora do Centro de Estudos Sociais da Universidade de Coimbra. Doutora pela Universidade de Cambridge; Email: teresacravo@ces.uc.pt.
}

\section{Resumo}

Definida como a nova prioridade da ONU em 1992, a consolidação da paz procurou responder ao desafio de um número crescente de guerras civis particularmente violentas e tornou-se, desde então, numa das mais visíveis e exigentes áreas de atuação da organização. $\mathrm{O}$ empenho na promoção ativa da resolução desses conflitos foi, no entanto, revelando graves debilidades e não impediu evidentes fracassos. Nestas duas décadas, o chamado paradigma da paz liberal tem vindo a sofrer críticas contundentes e é atualmente alvo de um ceticismo generalizado. Este artigo explora algumas dessas críticas apontadas ao modelo vigente, argumentando que, apesar de certas alterações ao conceito e prática da consolidação da paz, os problemas mais acutilantes estão ainda por resolver, e as mudanças até agora introduzidas não chegam a pôr em causa os pressupostos culturais e ideológicos, assim como os interesses práticos do Norte Global, que subjazem à promoção da paz na periferia.

Palavras-chave: Consolidação da paz. ONU. Paz liberal. Críticas.

\begin{abstract}
Defined as the United Nation's new priority in 1992, peacebuilding attempted to answer the challenge posed by an increasing number of particularly violent civil wars. It has become, since then, one of the most visible and demanding areas of the organisation's work. Efforts to actively promote conflict resolution over the following two decades, however, have often failed and suggest serious shortcomings in the very conceptual models underpinning international interventions. Throughout this period, the so-called liberal peace paradigm has suffered trenchant criticisms and is currently the target of widespread scepticism. This article explores some of those criticisms to the existing model and argues that, notwithstanding certain alterations to the concept and practice of peacebuilding, the most acute problems remain unresolved. Moreover, the changes so far introduced in response to critiques have largely failed to question the cultural and ideological assumptions, as well as the practical interests, of the Global North, which continue to underpin the promotion of peace in the periphery.
\end{abstract}

Keywords: Peacebuilding. United Nations. Liberal peace. Critiques. 


\section{Introdução}

Os conflitos violentos nos chamados Estados falhados que assolaram a periferia na década de 1990 foram considerados a maior ameaça à paz e segurança internacionais do pós-Guerra Fria, desafiando a comunidade internacional em geral, e a Organização das Nações Unidas (ONU) em particular, a responder às crises securitárias e humanitárias por eles geradas. Até então limitada na sua abordagem ao congelamento e contenção da violência no Sul Global, uma nova era de ativismo impulsionou uma maior ambição na Agenda para a Paz da organização, que se traduziu na emergência de um modelo de consolidação da paz de natureza multidimensional e orientado para a erradicação das causas profundas dos conflitos.

Não obstante a amplitude e fluidez das suas várias definições ao longo dos anos, ${ }^{2}$ a consolidação da paz pode ser definida numa ideia essencial: a criação de condições para uma paz auto-sustentada de forma a prevenir um retorno ao conflito violento. Esta ideia central poderia, em teoria, ter ganho várias formas; no entanto, fruto da conjuntura da altura em que foi concebida - no final da Guerra Fria - rapidamente se materializou na chamada "paz liberal". ${ }^{3}$ Nos últimos vinte anos, a ONU tem vindo a promover o sonho liberal na periferia, de criação de democracias pluripartidárias com economias de mercado $\mathrm{e}$ sociedades civis fortes - o que Kahler chama de "Consenso de Nova Iorque".

A realidade das sociedades devastadas pela guerra provou, todavia, ser mais complexa do que o antecipado pela organização mundial. Com uma trajetória repleta de sucessos contestados e alguns fracassos flagrantes, o modelo preconizado pelas $\mathrm{NU}$ tem sido alvo de duras críticas e de um ceticismo generalizado. Após uma breve análise de como emergiu o modelo de consolidação da paz das $\mathrm{NU}$, este artigo pretende essencialmente explorar como têm sido avaliados os esforços internacionais de pôr fim à conflitualidade violenta no Sul Global, debruçando-se sobre o que chamamos aqui de primeira e segunda geração de críticas ao modelo implementado nos últimos vinte anos. $\mathrm{O}$ artigo argumenta que, apesar de algumas alterações no conceito e prática da consolidação da paz,

2 Sobre as várias definições do conceito de consolidação da paz, ver BARNETT et al., 2007; CHETAIL, 2009. as críticas mais acutilantes ao paradigma atual estão ainda por resolver, e as mudanças até agora introduzidas não chegam a pôr em causa os pressupostos culturais e ideológicos, assim como os interesses práticos do Norte Global, que subjazem à promoção da paz na periferia.

\section{Os primórdios da consolidação da paz:}

\subsection{Os novos desafios}

No início da década de 1990 gerou-se um consenso entre académicos, centros de decisão internacional e profissionais no terreno, no que diz respeito às grandes tendências do pós-Guerra Fria, já visíveis desde a Segunda Guerra Mundial mas que o fim do sistema bipolar veio claramente intensificar. Em primeiro lugar, o declínio significativo no número de guerras inter-estatais relativamente ao aumento dramático de conflitos internos; ${ }^{4}$ em segundo lugar, a incidência dessa conflitualidade no chamado Terceiro Mundo - uma categoria tradicionalmente aplicada ao continente asiático, latino-americano e africano e agora expandida para abarcar os novos Estados do Cáucaso, da Ásia central, e dos Balcãs que emergiam da fragmentação da União Soviética e da Jugoslávia (AYOOB, 1996); e em terceiro lugar, o entendimento que estas "novas guerras" (KALDOR, 1999) eram o claro resultado do processo de construção e fracasso do Estado e apontavam para uma concentração desproporcional da violência do sistema internacional nos chamados Estados falhados (SNOW, 1996, p. 3).

O fracasso destes Estados incidia essencialmente na resistência às suas tentativas de centralização do poder militar, político, económico e social e na contestação da autoridade e legitimidade do governo central. A proliferação de entidades sub-estatais armadas acelerava a erosão do poder estatal, retirando-lhe o suposto monopólio do uso legítimo da força, partes do território e a sua capacidade para extrair recursos e satisfazer as necessidades básicas das populações. Esta substituição da presença

4 De acordo com os números apresentados por Wallensteen e Sollenberg (2001), dos 111 conflitos armados ativos durante o período de 1989-2000, apenas sete correspondiam ao paradigma de conflito inter-estatal. O Uppsala Conflict Data Program contabiliza como "conflito armado" aqueles que envolvem duas ou mais partes, uma das quais o governo de um Estado, e que resultam em 25 ou mais mortes em combate num ano. ver $<$ http://www.pcr.uu.se/research/UCDP/>. 
física e institucional do Estado pela de grupos sectários que passavam a desempenhar as suas funções de contrato social abria caminho à criação de laços de lealdade identitária dentro de comunidades crescentemente fora do controlo do poder central. Nestas circunstâncias, o Estado, no seu sentido Weberiano, enfrentava problemas internos difíceis que ameaçavam a sua ordem política e a sua própria existência, com graves consequências para a estabilidade regional e internacional. ${ }^{5}$

\subsection{A reação da comunidade internacional}

A mudança na natureza dos conflitos e o aumento dramático do seu número na era do pós-Guerra Fria suscitou uma reação vigorosa por parte da comunidade internacional e das NU. O seu inédito envolvimento na década de noventa foi, no entanto, produto de uma conjugação de fatores, facilitados pela radical alteração da conjuntura mundial.

Um primeiro fator remete-nos para o entendimento generalizado destas guerras enquanto disseminadas, destabilizadoras e imorais. Não obstante o número de guerras civis ter vindo a aumentar consistentemente desde a Segunda Guerra Mundial, só o fim da confrontação bipolar permitiu finalmente olhar para este fenómeno como a maior ameaça à paz e à segurança internacionais, quando, em 1991, se espalhava por 50 países nos vários continentes (WALLENSTEEN; SOLLENBERG, 2001, p. 632).

Além desta percepção de disseminação, constatava-se igualmente que, apesar de internas, raramente estas novas guerras permaneciam "hermeticamente seladas" (BROWN, 1996, p. 572), isto é, isoladas dentro das suas fronteiras. Incapazes de garantir a impenetrabilidade das suas fronteiras ou ativamente compactuando com os atores do conflito, os países vizinhos viam-se inevitavelmente envolvidos na evolução das confrontações, que se alargavam, assim, ao resto da região. Estas guerras civis tinham igualmente implicações diretas para os interesses das médias e grandes potências, que inevitavelmente se posicionavam em relação às partes em conflito, fosse para proteger os seus nacionais nesses territórios, manter o acesso a recursos estratégicos ou defender aliados

\footnotetext{
5 Sobre o tema dos Estados falhados, ver JACKSON, 1990; HELMAN e RATNER, 1992-1993; ZARTMAN, 1995; RENO, 1999; ROTBERG, 2004. Para uma perspetiva mais crítica do conceito, ver, por exemplo, BILGIN; MORTON, 2002; CALL, 2008 E 2011; VERHOEVEN, 2009.
}

políticos. A própria escalada da violência era alimentada externamente, através do tráfico internacional de armas, recursos naturais e drogas. ${ }^{6}$

Além de perturbar a ordem regional e internacional, estas guerras pareciam pôr também em causa o regime de normas internacionais de comportamento criado pela comunidade de Estados. Embora todos os conflitos travados ao longo da história tenham uma componente de "guerra suja", as práticas de abusos de direitos humanos e a cultura do terror manifestavam-se como uma característica central do modo de condução destas novas guerras, e contrária ao direito internacional que havia procurado nas décadas precedentes formular regras legais para diminuir a amplitude e o impacto dos conflitos armados, especialmente sobre os não-combatentes. ${ }^{7}$ Esta imoralidade do ataque indiscriminado e em larga escala às populações agitou consciências, em particular no Ocidente, e foi criando uma corrente favorável à punição e dissuasão deste tipo de conduta. Crucial para dar força a este movimento foi, na altura, a globalização dos media e a produção do chamado "efeito CNN", mostrando imagens devastadoras de violência e desastres humanitários, influenciando, assim, a opinião pública e, em última análise, as decisões governamentais. ${ }^{8}$

É essencial, no entanto, referir um terceiro fator que cria as condições culturais para esta forma de entender os conflitos e as normas internacionais: o triunfo do liberalismo com o final da Guerra Fria (JAKOBSEN, 2002). A ênfase liberal nos indivíduos, nos direitos humanos e na democracia, o surgimento do conceito de segurança humana, e o consequente entendimento da soberania enquanto expressão de responsabilidade aumentou drasticamente o papel dos atores externos em situações onde o Estado era incapaz ou não queria proteger os seus nacionais (DAWN, 2001, p. 124-125). Isto é particularmente evidente no contexto do fracasso do Estado, onde a

6 Sobre a economia política dos conflitos armados do pósGuerra Fria, ver DUFFIELD, 1994; KEEN, 1998; KALDOR, 1999; COLLIER, 2000; BERDAL; MALONE, 2000; BALLENTINE; SHERMAN, 2003; PUGH, COOPER e GOODHAND, 2004.

7 Sobre as culturas de violência da conflitualidade do pós-Guerra Fria, ver NORDSTROM; MARTIN, 1992; NORDSTROM, 1994; FETHERSTON, 1995; TILLY, 2003; CRAMER, 2006; KALYVAS, 2006; WEINSTEIN, 2007.

8 Sobre os media e o seu poder de influência, ver HOGE, 1994; SHAW, 1996; LIVINGSTON, 1997; ROBINSON, 2002. 
erosão de uma autoridade central efetiva - um fenómeno entendido como uma "descida ao estado hobbesiano de anarquia" (YANNIS, 2002, p. 822) - colocava em perigo a segurança física das populações e tinha consequências humanitárias gravíssimas.

Estes vários fatores conjugaram-se para eventualmente tornar as guerras intraestatais da década de noventa em guerras da comunidade internacional. Neste contexto de apelo a uma maior determinação na garantia da paz e da segurança internacionais, há claramente uma preferência por uma presença mais forte das NU nesta periferia instável. Enquanto que a ordem bipolar não tinha favorecido o envolvimento neste tipo de conflitos, a mudança dramática nas relações entre as superpotências, e a consequente maior cooperação no interior do Conselho de Segurança (CS), levou a um ressurgimento do intervencionismo, permitindo às NU finalmente assumir o papel que os seus fundadores tinham ambicionado (MIALL; RAMSBOTHAM; WOODHOUSE, 1999, p. 2). Boutros-Ghali, um Secretário-Geral (SG) particularmente ativo e interessado em catapultar a atuação da organização que liderava, aproveitou este momento de otimismo multilateral e apresentou uma proposta inovadora para fazer face aos desafios à paz e à segurança internacionais da era pós-Guerra Fria.

Clarificando o renovado entendimento da organização em matéria de promoção da paz na periferia, a sua Agenda para a Paz (1992) ensaia um modo de atuação mais ousado, coerente e dinâmico e que confere à organização uma considerável proeminência relativamente às décadas precedentes. Este modelo de institucionalização da paz segue de perto a proposta teórica do fundador dos Estudos para a Paz, Johan Galtung (1976) ${ }^{9}$ e avança com quatro estratégias de ação interligadas: a diplomacia preventiva (preventive diplomacy), o restabelecimento da paz (peacemaking), a manutenção da paz (peacekeeping) e a consolidação da paz (peacebuilding).

Ao voltar a sua atenção para o fenómeno da proliferação de conflitos internos nos "novos territórios nãoautónomos", como lhes chamaram Helman \& Ratner (1992-1993, p. 17), a ONU envolveu-se na promoção ativa

9 Sobre a forma como as propostas dos estudos para a paz transitaram para o discurso e a agenda política dos centros de decisão internacionais, ver LAWLER, 2002; PUREZA; CRAVO, 2005; PUREZA, 2011. da sua resolução pacífica, estimulando o diálogo continuado entre as facções opostas, acompanhando de perto as negociações dos acordos políticos e comprometendo-se a apoiar a implementação dos processos de paz resultantes desses acordos negociados. Atuando enquanto garante externo que assegura a responsabilização das partes ao longo do processo, a organização comprometeu-se com o pós-acordo de paz, enviando operações de manutenção da paz para variados contextos e em diferentes continentes - da Bósnia a Angola, do Camboja a El Salvador criando, assim, as condições para o envolvimento da organização em todas as fases do conflito, da prevenção à consolidação da paz pós-conflito.

\subsection{O modelo de consolidação da paz}

Para fazer face à complexa realidade de países pósconflito, o modelo de resposta procurou ser o mais institucionalizado possível, de forma a dirimir as incertezas e a volatilidade do ambiente pós-acordo de paz. Este novo quadro de resposta, codificado na Agenda para a Paz, inclui pela primeira vez o conceito de "consolidação da paz pós-conflito" como a nova prioridade da Organização, definida como "ações para identificar e apoiar estruturas que fortaleçam e solidifiquem a paz, de forma a evitar um retorno ao conflito" (UN, 1992, \$21). Este conceito engloba, assim, duas tarefas diferentes mas simultaneamente complementares: por um lado, a tarefa negativa de evitar um retorno à guerra; e, por outro, a tarefa positiva de lidar com as causas profundas do conflito, sem a qual o fim da violência não seria mais do que temporário (RAMSBOTHAM, 2000, p. 171-175). No seu sentido mais lato, a consolidação da paz pretendia "enfrentar as causas profundas do conflito: o desespero económico, a injustiça social e a opressão política" (UN, 1992, §15). A consolidação da paz far-se-ia, numa primeira fase, dentro do quadro das operações de manutenção da paz de segunda geração enviadas na sequência de acordos de paz (COCKELL, 2000, p. 20) e, numa segunda fase, com o auxílio dos atores externos, a responsabilidade transitaria progressivamente para os nacionais dos países a emergir de conflitos.

O envolvimento das NU na Namíbia, ainda em 1989, representa o nascimento deste novo paradigma de consolidação da paz. O relativo sucesso da missão atestou a capacidade da organização para realizar sucessivas operações de paz, com tarefas muito para além das tradicionais, em larga escala e numa grande variedade de países que emergiam de conflitos na Ásia, África, Europa e 
América Central na década de noventa (HAN, 1994, p. 842-845). Estas sucessivas operações foram responsáveis pela dramática expansão do papel das NU, seguindo amplamente o modelo implementado na Namíbia, variando unicamente em detalhes. Esta resposta padronizada - que Ramsbotham apelida de "UN's post-settlement peacebuilding standard operating procedure" (2000, p. 170) materializou-se no terreno com uma multiplicidade de atores e de tarefas que podem ser divididas em quatro dimensões interdependentes: (1) militar e de segurança, (2) político-constitucional, (3) económico-social, e (4) psico-social.

Este novo intervencionismo estandardizado e à escala global assumiu o modelo da chamada paz liberal. Como Clapham (1998, p. 193-194) esclarece, os vitoriosos do conflito bipolar - não só as democracias capitalistas e liberais, mas também as suas sociedades civis, e a grande massa de organizações não-governamentais e instituições internacionais que estas controlam - procuraram reestruturar o sistema internacional em conformidade com os valores que emergiam triunfantes nessa altura. Os promotores da Nova Ordem Mundial apresentaram a democracia liberal e a economia de mercado como as "receitas globais para o desenvolvimento, a paz e a estabilidade" (YANNIS, 2002, p. 825), baseando, assim, as concepções fundamentais da consolidação da paz no paradigma liberal. A queda do bloco socialista e do seu modelo alternativo permitiu que esta abordagem fosse abundantemente incentivada, e mesmo imposta, sem rival, nos quatro cantos do mundo - o que Lizée (2000) chama de "síndrome do Fim da História”. Introduzindo condicionalidades políticas e económicas através das operações de paz e dos programas de assistência ao desenvolvimento, o modelo das democracias de mercado foi se difundido por todo o Terceiro Mundo (JAKOBSEN, 2002). Neste sentido, como refere Paris, a consolidação da paz era efetivamente "uma enorme experiência de engenharia social - uma experiência que envolve a transplantação de modelos ocidentais de organização social, política e económica para países devastados pela guerra de forma a controlar o conflito civil: por outras palavras, a pacificação através da liberalização política e económica” (1997, p. 56).

\section{A primeira geração de críticas à consolidação da paz}

Ainda não tínhamos chegado ao final da primeira metade da década e a "euforia do início dos anos 1990" já havia dado lugar a desilusão (BROWN, 1996, p. 11) e um pessimismo generalizado anunciava uma nova era de anarquia na periferia (KAPLAN, 1994). Os dramáticos e mediáticos fracassos das missões em Angola, na Bósnia, na Somália e no Ruanda, em especial, acicataram uma profunda preocupação com o desempenho e a eficácia da promoção da paz no Sul Global.

A atuação das NU parecia, de facto, bastante aquém das (altas) expectativas. Em várias ocasiões, os acordos formais permaneceram bastante frágeis e as operações de paz não foram suficientes para impedir o retorno das hostilidades - um fracasso que provocaria, aliás, nos casos do Ruanda e de Angola, ainda mais violência do que as guerras que haviam antecedido as respetivas missões. As estatísticas sobre a reincidência de conflitos violentos em sociedades previamente devastadas pela guerra eram devastadoras - cerca de $50 \%$ nos primeiros cinco anos que se seguem à assinatura do acordo de paz (COLLIER, 2003, p. 83; CALL; COOK, 2003, p. 240) questionando abertamente o modelo intervencionista das NU. Mesmo em casos menos flagrantes, em que não se deu o regresso ao conflito armado, a materialização da paz formal foi perdendo terreno e a declaração de sucesso provou ser prematura. Com o passar dos anos, várias das "histórias de sucesso" iniciais foram sendo contestadas, de forma mais ou menos crítica, por estudos académicos e de organizações no terreno - como por exemplo, Moçambique (HANLON, 1996; WEINSTEIN, 2002), El Salvador (BOYCE, 1995; KINCAID, 2000) ou Camboja (DOYLE, 1995; LIZÉE, 2000) - contribuindo assim para a descrença no modelo e no seu ator fundamental.

\subsection{As críticas ao ator e às missões}

Enquanto principal protagonista deste paradigma de resposta em variados conflitos a partir da década de noventa, a ONU viu as suas falhas internas salientadas como em grande parte responsáveis pelos reveses e fracassos deste ambicioso projeto. Académicos, decisores políticos e funcionários internacionais rapidamente deixaram claro que a complexidade dos problemas em matéria de paz e segurança enfrentados com o fim da Guerra Fria desafiavam abertamente a capacidade institucional da organização mundial. Logo em 1994, Soto e Castillo (1994, p. 69-70). vaticinavam que "embora novamente na moda" a organização estava numa situação de sobre-extensão, a braços com graves limitações, e questionavam a sua capacidade para estar à altura das necessidades. 
Um primeiro aspeto continuamente ressaltado era o famigerado problema das restrições financeiras da organização, de forma geral acompanhado da habitual relutância dos Estados-membros em contribuir financeiramente para cada uma das missões em concreto, especialmente em contextos onde os seus interesses nacionais eram mais difusos. Um segundo aspeto dizia respeito ao défice de recursos humanos qualificados e com a experiência necessária para assegurar as responsabilidades atribuídas pelos mandatos do CS. Como consequência direta destas duas falhas, as NU viam-se inevitavelmente debilitadas na sua capacidade para planear e concretizar operações desta envergadura (ROBERTS; KINGSBURY, 1993; DURCH, 1993).

A dificuldade de comunicação e coordenação entre a missão no terreno e a sede em Nova Iorque, entre departamentos e agências das NU, e entre os contingentes civis e militares, como exemplifica a missão em El Salvador (SOTO; CASTILLO, 1994, p. 74) ou no Camboja (BELLAMY et al., 2004), intensificava estes constrangimentos organizacionais que assolavam a ONU. Acrescia ainda uma deficiente recolha de informação - quase sempre insuficiente e apressada - o que implicava uma incapacidade por parte das NU para anteciparem as condições no terreno. Lakhdar Brahimi, conselheiro especial do SG, admitia que "infelizmente, as decisões mais importantes acabam por ser tomadas muito cedo, antes de termos o conhecimento suficiente para antecipar as suas implicações" (BRAHIMI, 2004).

Esta questão estava diretamente relacionada com a calendarização da missão prevista nos acordos de paz: um calendário por norma demasiado reduzido, o que implicava em quase todos os contextos uma corrida contra o tempo, com a urgência a condicionar drasticamente a necessária preparação da missão. Isto não impedia, todavia, o frequente envio tardio das tropas e restantes componentes das missões, deixando o período volátil entre a assinatura formal do acordo de paz e a presença de um garante externo à mercê da ação dos chamados "spoilers" (STEDMAN, 1997) - agentes que pretendem sabotar o acordo de paz. Berdal (1995) aponta ainda os arranjos ad hoc e a improvisação, assim como ligações pessoais a presidirem em larga medida à tomada de decisão no seio das missões. Além da entrada nestes países, também a ausência de uma estratégia de saída se confirmava problemática concretizada frequentemente de forma abrupta com a retirada dos contingentes internacionais imediatamente após a realização das eleições (HIRSCHMANN, 2012).

$\mathrm{Na}$ ausência de força própria, o aumento dramático do número de operações na década de noventa havia exigido, por sua vez, o aumento no número de países contribuidores. Esta carência implicou fechar os olhos aos interesses explícitos de vários dos Estados em intervir no país-alvo, o que, por vezes, contribuiu para uma certa ambiguidade que pôs em causa a imparcialidade e a isenção da intervenção. Também fruto desta amálgama de países contribuidores, a experiência mista e o desfasamento em termos de formação dos contingentes tiveram repercussões negativas, ao nível operacional, para a coordenação entre membros da mesma missão (ROWE, 2000).

Porventura, o mais grave desta falta de critérios de seleção teve como consequência a ausência de controlo e responsabilização do comportamento das tropas e dos funcionários internacionais. Exemplos de abuso de poder, diminuta sensibilidade relativamente à cultura e costumes locais e, em casos extremos, escândalos graves, como o aumento exponencial da prostituição e da SIDA e relatos de abuso sexual ligados à presença das missões, da Bósnia ao Camboja (SAVE THE CHILDREN, 2008), manchavam a reputação das missões. Este tipo de comportamento permaneceu quase sempre por sancionar uma prerrogativa, aliás, que pertence não às NU mas ao país contribuidor, o que é em si mesmo inibidor da responsabilização do agressor. Estes casos criaram ressentimento na população local relativamente às operações de paz, minando a credibilidade e capacidade de intervenção da missão aos olhos daqueles que eram os principais visados e, acima de tudo, pondo em causa a legitimidade da organização mundial.

Um outro problema, diretamente ligado, referiase ao impacto do envio de soldados para sociedades já por si excessivamente militarizadas. A experiência dos contingentes militares enviados provara ser desajustada, com tropas treinadas para a guerra enviadas, sem formação adicional, para construir a paz e em contextos culturalmente distintos - uma carência que alertava para a escassa produção teórica sobre este tema, tanto ao nível da organização como dos próprios países contribuidores (FETHERSTON, 1995). Por outro lado, e especialmente na sequência de fracassos flagrantes como o Ruanda, debatia-se a pertinência dos princípios da restrição do uso da força e da imparcialidade (RATNER, 1995; DIEHL, 
2008). De facto, em circunstâncias onde o uso da força somente em legítima defesa não parecia ser suficiente para se conseguir cumprir o mandato estipulado e a responsabilidade administrativa não tinha correspondência em termos de poder no terreno face às partes hostis, a missão ficava claramente amputada para assumir o seu papel; a sugestão de um incremento da força musculada da missão chocava, porém, com a necessidade de preservar a distinção entre manutenção e imposição da paz (peace enforcement), e garantir o consentimento entre as partes antes do envio das tropas (BERDAL, 1993; LIPSON, 2007).

A operacionalização da proposta das NU para a paz e a segurança internacionais confirmava, assim, desde o início, debilidades flagrantes na sua capacidade de cumprir este ambicioso papel e dilemas difíceis de resolver que se prolongariam pelos anos seguintes.

\subsection{As críticas ao paradigma}

Mesmo na ausência de um órgão central de coordenação de todas as atividades de consolidação da paz durante a primeira década, houve desde o início uma convergência em torno de uma estratégia geral de construção da paz através da promoção da democracia liberal e da economia de mercado (PARIS, 2004). As críticas mais contundentes foram, sobretudo, as apontadas a esse modelo dominante da paz liberal.

Logo em 1997, Paris questionava se este tipo de intervenção externa construía efetivamente a paz, apontando para o paradoxo dos instrumentos da consolidação da paz serem, eles mesmos, destabilizadores para as sociedades intervencionadas. Usando como exemplos os casos do Ruanda, Angola, Bósnia, Moçambique, El Salvador e Nicarágua, Paris apontava para os efeitos perversos da rápida liberalização política e económica consubstanciada na paz liberal, chamando a atenção para a natureza conflituosa da democracia e do capitalismo - inerentemente promotores de competição dentro de sociedades pouco apetrechadas, dada a história recente de violência, para gerir de forma pacífica essa polarização (1997, p. 57). Embora não advogue o fim do intervencionismo liberal, a sua conclusão responsabilizava claramente as políticas de liberalização pelo exacerbar das tensões nestas sociedades, sugerindo, por isso, uma falha grave no desenho da consolidação da paz (PARIS, 1997; 2004).

Outros autores também se juntaram a estas críticas durante a segunda metade da década de noventa e nos anos seguintes, à medida que este fenómeno se tornava mais evidente. Do ponto de vista da reconstrução política destes Estados, era visível a existência de variados riscos do processo de democratização: o retorno à violência (nomeadamente na sequência da perda de eleições), a criação de democracias iliberais (com a legitimação eleitoral de regimes autoritários), o prolongamento de Estados frágeis (incapazes de edificar instituições democráticas inclusivas e plurais) e a ausência de transferência efetiva de poder democrático para os nacionais (como no caso dos protetorados) exemplificavam as dificuldades de pôr em prática, num curto espaço de tempo, a transição de Estados autoritários e pós-conflito para democracias liberais (OTTAWAY, 1995; THOMPSON, 1996; KUMAR, 1998; MANSFIELD; SNYDER, 2005; JARSTAD; SISK, 2008).

Do ponto de vista económico, a mera presença da missão - como referem Paris e Sisk (2009, p. 308), "um poderoso íman no meio de um campo magnético" - era, em si mesma, desestabilizadora para o país-alvo, produzindo um boom artificial que gera uma inflação massiva, promovendo um sector privado especulativo e favorecendo a imigração de minorias de países vizinhos mal aceites pela população local o que conduzia a tensões sociais e étnicas. A crítica mais contundente no final da década de noventa dizia, todavia, respeito às políticas macro-económicas de estabilização e regeneração por frequentemente entrarem em conflito com as prioridades da consolidação da paz (HANLON, 1996; CASTILLO, 2001). A austeridade do ajustamento estrutural precisamente quando seria necessária a canalização de recursos para a economia e os setores sociais colocava em risco estas sociedades pós-conflito, em alturas particularmente voláteis em que os dividendos da paz tardavam em se fazer sentir. Além disso, as políticas neoliberais do chamado Consenso de Washington - desregulação, liberalização e privatização - tinham mesmo um efeito contraproducente, acentuando a pobreza de largos segmentos da população e as desigualdades distributivas (que estavam na origem dos conflitos civis), tendo, por isso, um impacto social devastador e constrangedor de um desenvolvimento equitativo e inclusivo (GIBBON, 1996; KAISER, 1996).

A natureza padronizada do quadro de atuação foi igualmente alvo de críticas acutilantes. Tratando-se de um modelo único genericamente aplicado, era acusado de não deixar espaço para as especificidades locais nem 
para a emergência de soluções alternativas mais consentâneas com as diferentes realidades. Cingindo-se a reproduzir a sua clara matriz ocidental em países, na sua esmagadora maioria, não-ocidentais, esta abordagem refletia um esquema eurocêntrico pré-concebido, fechado a experiências multiculturais e a um maior papel dos agentes locais em determinar a agenda da reconstrução do seu próprio país. O fracasso na capitalização dos recursos locais, fruto de um modelo autoritário, top-down e estato-cêntrico, que negligenciava o grosso da população enquanto centralizava a tomada de decisão nos organismos internacionais e nas elites locais, impedia a construção de uma paz inclusiva, participada e, necessariamente, mais sustentável (LEDERACH, 1995; MCDONALD, 1997; CHOPRA, 2000).

\subsection{As reformas}

As várias críticas ao longo da década de noventa proporcionaram o necessário "choque com a realidade": isto é, a constatação de que as ambições do modelo de consolidação da paz eram mais difíceis de concretizar do que o esperado.

A organização procurou, entretanto agilizar o acompanhamento das missões através de reformas administrativas, como a criação do Departamento de Operações de Paz logo em 1992, da Comissão de Consolidação da Paz em 2005 e da Divisão de Política, Avaliação e Treino em 2007, e também através do recurso mais sistemático aos representantes especiais do SG. Embora estas inovações permitam, em teoria, uma melhor coordenação da entrada, permanência e retirada dos atores internacionais dos cenários de conflito e pós-conflito, as melhorias institucionais não têm conseguido resolver efetivamente os problemas de maior integração e coerência no seio das NU (BOUTELLIS, 2013). A organização procurou igualmente enfrentar as dificuldades em torno da formação dos peacekeepers, com a aprovação de uma estratégia geral do Serviço de Treino Integrado em 2008, mas também neste campo os esforços se mantêm até hoje numa fase embrionária (CUTILLO, 2013). Não obstante vários relatórios (UNSG, 2003) se referirem ao problema do comportamento sexual dos contingentes como endémico e revelador de uma cultura machista e de desigualdade de género dentro da ONU, Lipson aponta a incongruência entre um discurso normativo de tolerância zero e uma prática de negligência e impunidade - a que chama de "hipocrisia organizada" (LIPSON, 2007) - evidencian- do uma mentalidade que se tem revelado extraordinariamente difícil de alterar ${ }^{10}$.

Numa tentativa de colmatar algumas das suas carências em termos de recursos humanos e financeiros e ultrapassar restrições políticas e burocráticas, a ONU tem articulado o esforço de consolidação da paz com atores regionais, como a NATO ou a União Africana (GRIFFIN, 1999), tentando, porém, preservar a sua relevância doutrinária em termos de produção de normas e procedimentos internacionais. Importa, no entanto, perceber se esse aumento dos atores envolvidos significou maior paz e segurança internacionais ou se encorajou um sistema de standards duplos, dividindo a periferia em países mais ou menos estrategicamente relevantes, o que, em última análise, pode ameaçar a missão global das NU (BELLAMY; WILLIAMS, 2005, p. 193-195).

Ao longo dos anos, a incorporação das críticas à natureza destabilizadora do modelo da consolidação da paz não chegou efetivamente a questionar os fundamentos ideológicos da paz liberal: transformar países devastados por guerras civis em democracias liberais e de mercado. Na realidade, alguma adaptação ocorreu apenas ao nível da metodologia, com a adoção de reformas mais graduais - de "institucionalização antes da liberalização", tal como sugerira Paris (2004, p. 179) - de forma a construir e reforçar instituições de governação autónomas, eficazes e legítimas, antes da introdução de eleições winner-takes-all e de reformas drásticas de abertura ao mercado. Esta estratégia mais sensível aos efeitos perversos da "terapia de choque" mantinha, no entanto, os dois objetivos globais que presidiam à implementação do paradigma desde o início da década de noventa: (1) a reprodução do Estado ocidental weberiano na periferia - com o reforço da Reforma do Setor de Segurança, do Estado de Direito (rule of law) e da Boa Governação (os três pilares mais salientes do modelo na sua segunda década); e (2) a integração destes espaços na economia capitalista mundial - preservando genericamente o enquadramento neoliberal enquanto acautelavam o seu impacto sócio-económico mais devastador através de programas de apoio ao desenvolvimento e de combate à pobreza (HARRISON, 2004). Apesar da co-optação de

\footnotetext{
${ }^{10}$ Sobre a questão de género e as operações de paz ver BURCKHARDT, 2010; CAREY, 2001; MAZURANA et al., 2005; VAYRYNEN, 2004.
} 
alguma da retórica mais crítica - com a introdução de temas como a participação ou a apropriação na agenda da organização mundial (CAMPBELL, 2011) - o paradigma preservou, de facto, a sua matriz ocidental e a sua natureza hierárquica, centralizada e elitista.

\section{A segunda geração de críticas à consolidação da paz}

Ao longo da segunda década, as avaliações do paradigma de promoção da paz do pós-Guerra Fria foramse acumulando, animando o debate relativamente à conceção da intervenção e ao desempenho dos atores externos no Sul Global. O apontar das fraquezas persistentes do modelo e do seu principal protagonista permitiu um melhor entendimento dos múltiplos obstáculos à consolidação da paz, assim como das suas mais-valias. Face a este conhecimento acumulado, os vários autores foram-se posicionando relativamente ao teor e ao intuito das suas críticas. Nesta discussão, podemos identificar três protagonistas: (1) os problem-solvers, ${ }^{11}$ que embora reconhecendo defeitos relevantes no modelo advogam a sua continuidade, refinando o processo sem contestar o seu alicerce ideológico; (2) os críticos, que questionam a legitimidade do modelo em si, os seus valores, interesses e a reprodução de relações hegemónicas, desafiando, assim, a ordem aceite como realidade imutável.

\subsection{Os problem-solvers}

A maioria dos autores que se debruça sobre o tema da promoção da paz em Estados periféricos pertence ao chamado mainstream e pode ser rotulado de problem-solver - aquele que perfilha da ordem vigente, sugerindo unicamente orientações para lidar com os reptos recorrentes das políticas públicas em termos de planeamento, preparação, prioritização e recursos. No que concerne a consolidação da paz, estes são os autores preocupados em aumentar a relevância prática do modelo do internacionalismo liberal, aprender com os sucessos e os fracassos, propondo, nesse sentido, algumas reformas da abordagem vigente mas sempre dentro do enquadramento liberal. ${ }^{12}$

\footnotetext{
${ }^{11}$ Sobre o conceito de "problem-solver", ver COX, 1986.

${ }^{12}$ Ver, por exemplo, IGNATIEFF, 2003; FUKUYAMA, 2004; FORTNA, 2004, 2008; PARIS, 2004, 2010; CAPLAN, 2005; DOYLE; SAMBANIS, 2006; CALL; COUSENS, 2008; HOWARD, 2008; JARSTAD; SISK, 2008; BERDAL, 2009.
}

Não obstante os resultados decepcionantes, estes autores mantêm que a intervenção externa é mais benéfica do que prejudicial - ligando, nomeadamente, o declínio no número de conflitos na segunda década de implementação ${ }^{13}$ ao envolvimento internacional (FORTNA, 2004, 2008; HUMAN SECURITY CENTRE, 2005; DOYLE; SAMBANIS, 2006). Argumentam ainda que o ceticismo generalizado dos "híper-críticos" (PARIS, 2010) esquece que a alternativa é o abandono de milhões de pessoas da periferia a uma condição de insegurança e violência. Estes autores reconhecem, de uma forma geral, a lógica da missão civilizadora subjacente ao intervencionismo, que prepara estas sociedades para o auto-governo dentro do quadro liberal transplantando normas de governação do centro para a periferia (PARIS, 2002) - daí as analogias com o colonialismo que abordaremos em baixo - mas mantêm que as situações de transferência de poder para as instâncias internacionais continuam a ser preferíveis ao retorno à guerra. A sua preocupação reside, nesse sentido, no aperfeiçoamento do modelo aplicado, de forma a minimizar os efeitos destabilizadores e melhorar a sua eficácia.

Paris e Sisk (2009) resumem esta posição, afirmando a existência de contradições inerentes ao modelo de consolidação da paz com que as organizações envolvidas terão de aprender a lidar no dia-a-dia das intervenções. Estes autores apontam cinco contradições enraizadas na própria ideia de assistência externa à reconstrução do Estado: (1) a intervenção externa é utilizada para fomentar o auto-governo; (2) é necessário controlo internacional para criar apropriação local (local ownership); (3) valores universais são promovidos para resolver problemas locais; (4) o corte com o passado é concomitante com a afirmação da história; e, por último, (5) os imperativos de curto e de longo prazo entram frequentemente em conflito. Estas tensões materializam-se em desafios práticos ao nível da formulação de políticas, em matéria de definição de condições de legitimidade e autoridade, desenho das estruturas de governação, provisão de serviços à população, determinação da duração das missões, expectativas culturais, etc. (PARIS; SISK, 2009, p. 305-306). Os autores prosseguem esta análise formulando os dilemas enfren-

\footnotetext{
${ }^{13}$ De acordo com Themnér e Wallensteen (2011), em 2010, havia 30 conflitos armados ativos - um número consideravel-
} mente mais baixo do que os anos mais dramáticos do início da década de 1990 (atingindo o pico de 53 conflitos em 1992). 
tados no contexto da consolidação da paz: em termos de (1) presença internacional (isto é, o grau de ingerência nos assuntos internos do Estado de acolhimento - tamanho da missão, natureza das tarefas, condicionalidade/ imposição); (2) duração da missão (reconstrução pós-bélica enquanto atividade necessariamente de longo-prazo versus responsabilização dos atores nacionais); (3) participação local (elites versus população; prioridades internacionais versus prioridades locais); (4) dependência (dos atores internacionais versus paz auto-sustentada); (5) coerência (coordenação organizacional e consistência normativa) (PARIS; SISK, 2009, p. 306-309).

A constatação destes dilemas não leva estes autores a rejeitarem as missões da comunidade internacional na periferia instável. Pelo contrário, a análise dos dilemas enraizados na promoção da paz por parte dos próprios atores internacionais é uma forma "realista" de tentar equilibrar imperativos contraditórios, sendo que, em várias ocasiões, fazer menos, e não mais, pode ser a melhor opção - como se torna claro pela preferência destes autores pelo statebuilding em vez do peacebuilding (2009). A sua proposta é no sentido de "gerir", sendo que não se conseguirá resolver inteiramente, os dilemas da consolidação da paz, de forma a melhorar o seu desempenho e eficácia, ajustar as expectativas irrealistas e, assim, "salvar" o projeto da paz liberal (PARIS, 2010).

\subsection{Os críticos}

Por oposição a uma abordagem técnica orientada para uma maior eficácia, o horizonte dos autores críticos é transformativo, tendo como alicerce a resistência a formas hegemónicas de poder (DUFFIELD, 2001; PUGH, 2005; CHANDLER, 2006, 2010a; RICHMOND, 2006; MACGINTY, 2008; DARBY, 2009). Essa ambição normativa de transformação pode ser vista aqui sob dois ângulos, inevitavelmente interligados: o da transformação do modelo em si, por oposição a um ajustamento consentâneo com a preservação do paradigma dominante da paz liberal; e o da transformação do sistema mais alargado de relações de poder, por oposição à preservação do status quo.

Segundo Lidén (2011, p. 57), a paz liberal pode ser entendida pelo prisma pós-colonial como uma atividade que promove a cultura, identidade e normas ocidentais, em detrimento de outras, e reforça a assimetria de poder do Norte Global sobre o Sul Global - o que abre a consolidação da paz a analogias com o colonialismo. Estas perspectivas críticas veem nos problemas estruturais da conceção e implementação do modelo de consolidação da paz um reflexo das relações de poder desiguais no sistema internacional. As intervenções criam uma hierarquia clara entre interventores e intervencionados e atuam como instrumento da governação global do Ocidente na periferia, consolidando a sua hegemonia, defendendo os seus interesses geoestratégicos e promovendo os seus valores (CHANDLER, 2010b). Nesse sentido, a paz liberal funciona efetivamente como legitimação da ordem mundial que se seguiu à vitória do bloco ocidental da Guerra Fria, ao servir os interesses dos Estados ocidentais e das instituições financeiras internacionais por eles controladas. Segundo Duffield (2001, 2007) e Pugh (2005), as estratégias neoliberais de regulação, naturalizadas como soluções técnicas para a instabilidade, reproduzem ainda as condições dos conflitos e causam a própria violência que pretendem resolver.

Numa crítica aos críticos, Sabaratnam (2013, p. 263) aponta, no entanto, para uma forma insidiosa de etnocentrismo, em que o objeto de estudo permanece a intervenção em si, a sua trajetória, e não os sujeitos políticos das sociedades-alvo. Isto é, no seu entender, a definição e o enquadramento da análise, mesmo a análise crítica, realça a hiper-agência do Ocidente, centrando-se, quase que exclusivamente, nos interventores e suas práticas, marginalizando as pessoas e as suas experiências nos espaços onde se materializa a paz liberal. A autora defende que para "descolonizar" os próprios estudos críticos, é necessário dar voz às interpretações que os sujeitos em sociedades intervencionadas fazem das suas próprias circunstâncias e, para isso, para além de críticas à natureza das relações Norte-Sul, é preciso uma metodologia empírica mais próxima das populações (SABARATNAM, 2013, p. 273).

Richmond (2006, 2009, 2010, 2011a) e MacGinty (2008, 2010, 2011) procuraram encontrar um modelo de paz pós-liberal aberto às epistemologias do Sul e que supere a imposição do internacional sobre o local. O contributo destes dois autores consubstancia-se essencialmente na teoria da paz híbrida - aplicando ao campo da paz um termo conhecido dos estudos pós-coloniais e da antropologia - em que a paz é um híbrido cumulativo entre o local e o externo, isto é, uma fusão de longo prazo entre as forças endógenas e exógenas, um intercâmbio constante entre culturas e sociedades, entre o internacional e o do- 
méstico (MACGINTY, 2010; RICHMOND, 2011b). Recusando tanto a universalidade da paz liberal (enquanto princípio e prática) como a pureza do local, o hibridismo reconhece que nenhum ator, nem mesmo o ocidental apesar do seu poder relativo, consegue impor a sua visão e agenda inteiramente sobre o outro. Existe efetivamente agência local para resistir, subverter, renegociar, ignorar, atrasar e produzir alternativas.

Isto não significa que o processo de hibridização seja sempre e necessariamente positivo no que diz respeito à construção da paz - diferentes atores ou práticas interagem de forma diferente, em cooperação ou em conflito, com a paz liberal internacional, com diferentes resultados (MACGINTY, 2010, p. 406). O local não deve ser, por isso, romantizado ou entendido como inerentemente bom ou melhor somente por ser endógeno (PARIS, 2010; RICHMOND, 2011b). Por outras palavras, a síntese entre a construção da paz internacional e local é de geometria variável, por norma problemática, controversa e nãolinear. Este reconhecimento abre, no entanto, caminho para pensar construções do Estado e formas de governação de sociedades que podem tirar partido do enquadramento liberal mas que vão igualmente bastante para além dele, podendo criar uma multiplicidade de "pazes", por oposição à paz liberal hegemónica.

A ideia é então de concentrar esforços no que alguns autores chamam de formas diárias e populares de paz (RICHMOND, 2009; MACGINTY, 2013; ROBERTS, 2012), orientando o "envolvimento solidário" (CAMPBELL, 2011, p. 40) para dinâmicas locais de participação e governação tendentes ao estabelecimento de relações pacíficas. Este modelo seria assim baseado no consentimento e guiado pelas necessidades locais, por oposição ao paradigma liberal imposto através da força, da condicionalidade e da dependência que conduz a uma "paz virtual", top-down, em vez de uma paz real e bottom-up (RICHMOND, 2009, p. 263). A mudança de paradigma permitiria, igualmente, reequilibrar a relação de forças entre o global e o local e potenciar uma paz mais sustentável (ROBERTS, 2012, p. 372; TADJBAKHSH, 2011).

Embora a tentativa de repensar as relações entre o local e o internacional no seio da consolidação da paz seja uma proposta válida e relevante para o debate, os defensores do modelo híbrido da paz pós-liberal caem, porém, em algumas armadilhas. Grande parte desta proposta, pretendendo afastar-se da escolha impossível entre não-intervenção e intervenção liberal, acaba por não discutir efetivamente a necessidade do intervencionismo, preferindo centrar-se antes na inclusão do local no internacional. Isto não só mantém, mais do que estes mesmos autores pretenderiam em teoria, a distinção artificial entre local e internacional, como acaba por permear a forma como entendem os estudos empíricos (SARABATNAM, 2013, p. 267). Acresce ainda que, como Chandler explica, esta discriminação de categorias parece sugerir que o problema da paz liberal é ser "demasiado liberal" - o que, além de reificar a distinção entre o "eu ocidental liberal" e o "outro não-ocidental e não-liberal", remete a crítica para as aspirações liberais (que podem ser emancipatórias), em vez de para as práticas impositivas do intervencionismo, sem expor alternativas concretas e progressistas de transformação social (CHANDLER, 2010b, p. 144-146, 152-153).

\section{Conclusões}

Passados vinte anos, o futuro da consolidação da paz permanece em dúvida: ao mesmo tempo que se espalhou uma vaga de desconfiança relativamente aos esforços internacionais de promoção da paz na periferia, os pedidos de intervenção externa continuam a proliferar (PARIS, 2010; PARIS; SISK, 2009, p. 314-315).

Avaliar o sucesso da consolidação da paz é inerentemente um exercício relativo, que tem de ser contraposto ao conceito subjacente de paz. A resposta aos conflitos do pós-Guerra Fria evidencia claramente uma abordagem que vai para além do modelo militar tradicional, integrando as dimensões político-constitucional, económico-social e psico-social, sem as quais um acordo de cessar-fogo não seria mais do que temporário. $\mathrm{O}$ enquadramento do novo tipo de intervencionismo que emerge na década de noventa é, nesse sentido, claramente mais ousado - e, por isso mesmo, mais permeável ao fracasso. Acresce ainda que este envolvimento internacional em países sem capacidade para se reabilitarem sozinhos da destruição causada pela guerra pode ser visto, de forma positiva, como uma manifestação da ideia de responsabilidade partilhada: isto é, um barómetro do compromisso da sociedade internacional para com os infortúnios da periferia e o seu apoio a iniciativas conducentes a uma paz sustentável.

Todavia, reconhecer o nível de ambição deste modelo - de mero congelamento dos conflitos à tentativa de 
resolução das suas causas profundas - e a necessidade de auxílio internacional a sociedades devastadas pela guerra não implica deixar de reconhecer que a maior parte das críticas apontadas ao longo destes vinte anos mantém ainda hoje a sua validade. Embora de natureza e com intuitos diferentes, como vimos em cima, as críticas põem efetivamente em causa: (1) a bondade do modelo de intervenção - chamando a atenção para as características imperialistas do paradigma e a forma como serve os interesses e agendas particulares do Norte nos países do Sul; (2) a sua natureza - contestando a centralidade da segurança (que privilegia ordem e estabilidade em detrimento de emancipação) e a sua essência elitista, tecnocrática e padronizada; (3) a sua legitimidade - questionando a assunção ocidental da universalidade do liberalismo, a sua abordagem eurocêntrica, impositiva e constrangedora da participação local; e (4) a sua eficácia - sublinhando as relações de dependência para com os atores externos, as consequências da desvalorização do contributo endógeno e as lacunas institucionais da organização mundial para assumir o mandato global que o novo paradigma de resposta aos conflitos armados lhe proporciona.

O importante debate sobre as limitações e as mais-valias do modelo de promoção da paz na periferia é naturalmente bem-vindo. Tem permitido introduzir alguma auto-crítica e consequente dinâmica no conceito e prática internacionais de assistência a sociedades em transição, produzindo mesmo alguns ajustes claramente favoráveis no sentido de um modelo mais flexível e aberto a novas abordagens. Na prática, porém, a separação do paradigma liberal estandardizado, por um lado, do compromisso internacional para a consolidação da paz, por outro, está ainda por emergir; e, neste momento, essa ausência parece estar ainda a uma grande distância de ser colmatada.

\section{Referências}

AYOOB, Mohammed. State-Making, State-Breaking and State Failure: Explaining the Roots of 'Third World' Insecurity. In: GOOR et al. (Ed.). Between Development and Destruction: an Enquiry into the Causes of: conflict in post-Colonial States. London: MacMillan Press, 1996. p. 67-90.

BALLENTINE, Karen; SHERMAN, Jake (Ed.). The Political Economy of Armed Conflict: beyond greed and Grievance. Boulder: Lynne Rienner Publishers, 2003.
BARNETT, Michael et al. Peacebuilding: What Is in Name? Global Governance, Boulder, Colorado, USA, n. 13, p. 35-58, 2007.

BELLAMY, Alex; WILliAMS, Paul. Who's Keeping the Peace? Regionalization and Contemporary Peace Operations. International Security, Cambridge, Massachusetts, USA, v. 29, n. 4, p.157-195, 2005.

BELLAMY, Alex; WILLIAMS, Paul; GRIFFIN, Stuart. Understanding Peacekeeping. Cambridge: Polity Press, 2004.

BERDAL, Mats. Building Peace After War. The Adelphi Papers, London: Routledge, v. 49, n. 407, 2009.

BERDAL, Mats. Reforming the UN's Organisational Capacity for Peacekeeping. In: THAKUR; THAYER (Ed.), A Crisis of Expectations: UN Peacekeeping in the 1990s. Boulder, Colorado, USA: Westview Press, 1995. p. 181-192.

BERDAL, Mats. Whither UN Peacekeeping, The Adelphi Papers, London: Routledge, v. 33, n. 281, 1993.

BERDAL, Mats; MALONE, David. Greed and Grievance: economic agendas in Civil Wars. Boulder, Colorado, USA: Lynne Rienner Pubs, 2000.

BILGIN, Pinar; MORTON, Adam. Representations of 'Failed States': Beyond the Cold-War Annexation of the Social Sciences? Third World Quarterly, London: Routledge, v. 23, n. 1, p. 55-80, 2002.

BOUTELLIS, Arthur. Driving the System Apart? A Study of the United Nations Integration and Integrated Strategic Planning. International Peace Institute Policy Paper, 2013. Disponível em: <http://www.ipinst.org/media/pdf/ publications/ipi_e_pub_driving_the_system_apart.pdf $>$. Acesso em: jun. 2013.

BOYCE, James. Adjustment Toward Peace: An Introduction. World Development, Philadelphia, Pensilvania, USA, v.23, n. 12, p. 2067-2077, 1995.

BRAHIMI, Lakhdar. Statement by Mr Lakhdar Brahimi, Special Adviser to the UN Secretary-General, on the Occasion of the Awarding of the Dag Hammarskjold Medal by the German UN Association. 2004. Disponível em: $\quad<$ http://www.un.org/apps/news/infocus/iraq/ infocusnews.asp?NewsID=767\&sID=9\#>. Acesso em: 15 de ago. 2013.

BROWN, Michael (Ed.). The International Dimensions of Internal Conflict. Cambridge: MIT Press, 1996. 
BURCKHARDT, Yosi. Sexual abuse by United Nations peacekeeping forces and the legitimacy of peace operations. In: HENRIKSSON (Ed.). Crisis Management Centre Finland Yearbook 2010. Kuopio, Finland: CMC Finland, 2010. p. 98-113

CALL, Charles. Beyond the 'failed state': Toward conceptual alternatives. European Journal of International Relations, Sussex, United Kingdom, v.17, n. 2, p. 303-326, 2011.

CALL, Charles. The Fallacy of the 'Failed State. Third World Quarterly, London: Routledge, v. 29, n. 8, p.14911507, 2008.

CALL, Charles; COOK, Susan. On Democratization and Peacebuilding, Global Governance, v. 9, n. 2 , p. 233-234, 2003.

CALL, Charles; COUSENS, Elizabeth. Ending Wars and Building Peace: International Responses to War-Torn Societies. International Studies Perspectives, v. 9, p. 1-21, 2008.

CAMPBELL, Stephen. Construing Top-Down as BottomUp: the governmental co-option of peacebuilding 'from Below', Vis-à-vis: Explorations in Anthropology, Toronto, Canada, v. 11, n. 1, p. 39-56, 2011.

CAPLAN, Richard. International Governance of WarTorn Territories: Rule and Reconstruction. New York: Oxford University Press, 2005.

CAREY, Henry. Women and peace and security: the politics of implementing gender sensitivity norms in peacekeeping. International Peacekeeping, London, United Kingdom, v. 8. n. 2, p. 49-68, 2001.

CASTILLO, Graciana. Post-Conflict Reconstruction and the Challenge to International Organizations: the Case of El Salvador. World Development, Philadelphia, Pensilvania, USA, v. 29, n. 12, p. 1967-1985, 2001.

CHANDLER, David. Empire in Denial: The Politics of State-building. London: Pluto, 2006.

CHANDLER, David. International Statebuilding: The Rise of Post-Liberal Governance. London: Routledge, 2010a.

CHANDLER, David. The uncritical critique of liberal peace. Review of International Studies, Cambridge, United Kingdom, v. 36, n.1, p. 137-155, October, 2010b.

CHETAIL, Vincent (Ed.). Post-Conflict Peacebuilding: a lexicon. Oxford: Oxford University Press, 2009.

CHOPRA, Jarat. The UN's Kingdom of East Timor, Survival, v. 42, n. 3, p.27-39, 2000.
CLAPHAM, Christopher. Rwanda: The Perils of Peacemaking. Journal of Peace Research, Oslo, Norway, v. 35, n. 2, p. 193-210, 1998.

COCKELL, John. Conceptualising Peacebuilding: human security and sustainable peace. In: PUGH (Ed.). Regeneration of War-Torn Societies. London: MacMillan Press, 2000. p. 15-34.

COLLIER, Paul et al. Breaking the Conflict Trap: Civil War and Development Policy. New York: Oxford University Press and World Bank, 2003.

COLLIER, Paul. Doing Well Out of War: an Economic Perspective. In: BERDAL; MALONE (Ed.). Greed and Grievance: economic agendas in civil wars. Boulder, Colorado, USA: Lynne Rienner, 2000. p. 91-111.

COX, Robert. Social Forces, States and World orders: beyond international relations theory. In: KEOHANE, Robert (Ed.). Neorealism and Its Critics. New York: Columbia University Press, 1986. p. 204-254.

CRAMER, Christopher. Civil War is Not a Stupid Thing: accounting for violence in developing countries. London: Hurst e Company, 2006.

CUTILlO, Alberto. Deploying the Best: Enhancing Training for United Nations Peacekeepers. International Peace Institute Policy Paper, 2013. Disponível em: <http:// www.ipinst.org/media/pdf/publications/ipi_epub_ deploying_the_best.pdf $>$. Acesso em: jun. 2013.

DARBY, Philip. Rolling Back the Frontiers of Empire: Practising the Postcolonial. International Peacekeeping, London: Routledge, v. 16, n. 5, p. 699-716, 2009.

DAWN, Renata. Armed conflict prevention, management and resolution. In: SIPRI Yearbook 2001: Armaments, Disarmament and International Security. Oxford: Oxford University Press, 2001. p. 69-127.

DIEHL, Paul. Peace operations. Cambridge: Polity Press, 2008.

DOYLE, Michael. Three Pillars of the Liberal Peace. American Political Science Review, Cambridge, Massachusetts, USA, v. 99, n. 3, p. 463-466, 2005.

DOYLE, Michael. Liberal Peace: Selected Essays. London: Routledge, 2011.

DOYLE, Michael. Peacebuilding in Cambodia. Boulder, Colorado, USA: International Peace Academy Occasional Papers \& Lynne Rienner Publishers, 1995. 
DOYLE, Michael; SAMBANIS, Nicholas. Making War \& Building Peace. Princeton, New Jersey, USA: Princeton University Press, 2006.

DUFFIELD, Mark. The Political Economy of Internal War: Asset Transfer, Complex Emergencies and International Aid. In: MACRAE; ZWI (Ed.). War and Hunger. Rethinking International Responses to Complex Emergencies. London: Zed Books, 1994.

DUFFIELD, Mark. Development, Security and Unending War: governing the world of peoples. Cambridge, United Kingdom: Polity, 2007.

DUFFIELD, Mark. Global Governance and the New Wars. The Merging of Development and Security. London: Zed Books, 2001.

DURCH, William (Ed.). The Evolution of UN Peacekeeping: case studies and comparative analysis. New York: St. Martin's Press, 1993.

FETHERSTON, A. Betts. UN peacekeepers and cultures of violence. Cultural Survival Quarterly, v. 10. n.1, p. 1923, 1995.

FORTNA, Virginia. Does Peacekeeping Keep Peace? International Intervention and the Duration of Peace After Civil War. International Studies Quarterly, Bloomington, Indiana, USA, v. 48, n. 2, p. 269-292, 2004.

FORTNA, Virginia. Does Peacekeeping Work? shaping belligerents' choices after civil war. Princeton, New Jersey, USA: Princeton University Press, 2008.

FUKUYAMA, Francis. State-building: governance and world order in the $21^{\text {st }}$ century. Ithaca, NY, USA: Cornell University Press, 2004.

GALTUNG, Johan. Three Approaches to Peace: peacekeeping, peacemaking, and peacebuilding. In: Peace, War and Defense: essays in peace research,. Copenhagen: Christian Ejlers, 1976. v. 2.

GIBBON, Peter. Structural Adjustment and Structural Change in Sub-Saharan Africa: Some Provisional Conclusions. Development and Change, v. 27, n. 4, p. 751784, 1996.

GRIFFIN, Michele. Retrenchment, Reform and Regionalisation: trends in un peace support operations. International Peacekeeping, London: Routledge, v.6, n. 1, p.1-31, 1999.

GUATEMALA: Convergences of Success and Crisis. Journal of Interamerican Studies and World Affairs, Malden, Massachussetts, USA, v. 42, n. 4, p.39-58, 2000.
HAN, Sonia. Building a Peace that Lasts: The United Nations and Post-Civil War Peacebuilding. New York University Journal of International Law and Politics, New York, NY, USA, v. 26, n. 4, p. 837-892, 1994.

HANLON, Joseph. Peace without Profit. How the IMF blocks rebuilding in Mozambique. Oxford, United Kingdom: James Currey, 1996.

HARRISON, Graham. The World Bank and Africa: the construction of governance states. London: Routledge, 2004.

HAYES, Jarrod. The Democratic Peace and the new Evolution of an old Idea. European Journal of International Relations, Sussex, United Kingdom, v.18, n. 4, p. 767-791, 2012.

HELMAN, Gerald; RATNER, Steven. Saving Failed States. Foreign Policy, Washington D.C. USA, n.89, p.320, 1992-1993.

HIRSCHMANN, Gisela. Organizational learning in United Nations' peacekeeping exit strategies. Cooperation and Conflict, California, USA, v. 47, n. 3, p. 368-385, 2012.

HOGE, James. Media Pervasiveness. Foreign Affairs, Tampa, Florida. USA, v. 73, n. 4, p.136-144, 1994.

HOWARD, Lise Marie. UN Peacekeeping in Civil Wars. Cambridge: Cambridge University Press, 2008.

HUMAN SECURITY CENTRE. Human Security Report. University of British Columbia, 2005. Disponível em: <www.humansecurityreport.info>. Acesso em: jul. 2013

IGNATIEFF, Michael. Empire Lite: Nation-Building in Bosnia, Kosovo and Afghanistan. London: Vintage, 2003.

JACKSON, Robert. Quasi-States: Sovereignty, International Relations and the Third World. Cambridge: Cambridge University Press, 1990.

JAKOBSEN, Peter Viggo. The transformation of United Nations Peace Operations in the 1990s: Adding Globalization to the Conventional 'End of the Cold War Explanation. Cooperation and Conflict, California, USA, v. 37, n. 3, p. 267-282, 2002.

JARSTAD, Anna; Sisk, Timothy (Ed.). From War to Democracy: Dilemmas of Peacebuilding. Cambridge: Cambridge University Press, 2008.

KAHLER, Miles. Statebuilding After Afghanistan and Iraq. In: PARIS, Roland; SISK, Timothy (Ed.). The Dilemmas of Statebuilding: confronting the contradictions of postwar peace operations. London: Routledge, 2009. p. 287-303. 
KAISER, Paul. Structural Adjustment and the Fragile Nation: the demise of social unity in Tanzania. Journal of Modern African Studies, v. 34, n. 2, p. 227-237, 1996.

KALDOR, Mary. New and Old Wars. Cambridge: Polity Press, 1999.

KALYVAS, Stathis. The logic of violence in civil war. Cambridge: Cambridge University Press, 2006.

KAPLAN, Robert. The coming Anarchy. The Atlantic, Boston, Massachusetts, USA, 1 February 1994.

KEEN, David. The Economic Functions of Violence in Civil Wars. Adelphi Paper, 320, International Institute of Strategic Studies. London: Oxford University Press, 1998.

KINCAID, Douglas. Demilitarization and Security in El Salvador and Guatemala: Convergences of Success and Crisis. Journal of Interamerican Studies and World Affairs, Malden, Massachussetts, USA, v.42, n. 4, p. 39-58, 2000.

KUMAR, Krishna. After the Elections: Consequences for Democratisation. In: KUMAR (Ed.). Postconflict Elections, Democractisation, and International Assistance. Boulder, Colorado, USA: Lynne Rienner, 1998. p.215227.

LAWLER, Peter. Peace Research, War, and the Problem of Focus. Peace Review, San Francisco, California, USA, v. 14, n. 1, p. 7-14, 2002.

LEDERACH, John Paul. Preparing for Peace: conflict transformation across cultures. New York: Syracuse University Press, 1995.

LIDÉN, Kristoffer. Peace, Self-governance and International Engagement: From Neo-colonial to Post-colonial Peacebuilding. In: TADJBAKHSH (Ed.). Rethinking the Liberal Peace: external models and local alternatives. New York: Routledge, 2011. p.57-74.

LIPSON, Michael. Peacekeeping: Organized Hypocrisy? European Journal of International Relations, Sussex, United Kingdom, v. 13, n. 5, p. 5-34, 2007.

LIVINGSTON, Steven. Clarifying the CNN Effect: An Examination of Media Effects According to Type of Military Intervention, Joan Shorenstein Center Research Paper R-18, 1997. Disponível em: <http://www.genocidewatch.org/images/1997ClarifyingtheCNNEffectLivingston.pdf $>$. Acesso em: 15 ago. 2013.

LIZÉE, Pierre. Peace, power and resistance in Cambodia. global governance and the failure of international conflict resolution. London: MacMillan Press, 2000.
MAC GINTY, Roger. Hybrid Peace: the Interaction between top-down and bottom-up peace. Security Dialogue, v. 41, n. 4, p. 391-412, 2010.

MAC GINTY, Roger. Indicators: A Proposal for Everyday Peace Indicators. Evaluation and Program Planning, v. 36, n.1, p. 56-63, 2013.

MAC GINTY, Roger. Indigenous Peace-Making Versus the Liberal Peace. Cooperation and Conflict, Sage Publications, California, USA, v. 43, n. 2, p. 139-163, 2008.

MAC GINTY, Roger. International peacebuilding and local resistance: Hybrid Forms of Peace. Basingstoke: Palgrave Macmillan, 2011.

MANSFIELD, Edward; SNYDER, Jack. Electing to fight: why emerging democracies go to war. Cambridge, Massachusetts, USA: MIT Press, 2005.

MAZURANA, Dyan; RAVEN-ROBERTS, Angela; PARPART; Jane (Ed.). Gender, Conflict, and Peacekeeping. New York, USA: Rowman and Littlefield Publishers, 2005.

MCDONALD, Geraldine. Peacebuilding from Below: alternative perspectives on Colombia's peace process. London: Catholic Institute for International Relations, 1997.

MIALL, Hugh; RAMSBOTHAM, Oliver; WOODHOUSE, Tom. Contemporary Conflict Resolution. Cambridge: Polity Press, 1999.

NORDSTROM, Carolyn. Warzones: Cultures of Violence, Militarisation and Peace. Working Paper, n.145. Canberra, Australia: Peace Research Centre, The Australian National University, 1994.

NORDSTROM, Carolyn; MARTIN, Joann (Ed.). The paths to domination, resistance and terror. Berkeley, California, USA: University of California Press, 1992.

NURUZZAMAN, Mohamed. Revisiting the Category of Fragile and Failed States in International Relations. International Studies, v. 46, n. 3, p. 271-294, 2009.

OTTAWAY, Marina. Democratisation in Collapsed States. In: ZARTMAN (Ed.). Collapsed States. the disintegration and restoration of legitimate authority. Boulder, Colorado, USA: Lynne Rienner Publishers, 1995. p.235-249.

PARIS, Roland. International Peacebuilding and the 'Mission Civilisatrice. Review of International Studies, Cambridge, United Kingdom, v.28, n. 4, p.637-656, 2002. 
PARIS, Roland. Peacebuilding and the Limits of Liberal Internationalism. International Security, Cambridge, Massachusetts, USA, v. 22, n. 2, p.54-89, 1997.

PARIS, Roland. Bringing the Leviathan Back In: Classical Versus Contemporary Studies of the Liberal Peace. International Studies Review, Cambridge, United Kingdom, v. 8, n. 3, p. 425-440, 2006.

PARIS, Roland. Saving Liberal Peacebuilding. Review of International Studies, Cambridge, United Kingdom, v. 36, n.2, p. 337-365, 2010.

PARIS, Roland. At War'sEnd: BuildingPeace after Civil Conflict. Cambridge: Cambridge University Press, 2004.

PARIS, Roland; SISK, Timothy (Ed.). The dilemmas of statebuilding: confronting the contradictions of postwar peace operations. London: Routledge, 2009.

PUGH, Michael. The Political Economy of Peacebuilding: a critical theory perspective. International Journal of Peace Studies, Oslo, Norway, v. 10, n. 2, p. 23-42, 2005.

PUREZA, José Manuel. O desafio crítico dos estudos para a paz. Relações Internacionais, v. 32, p. 5-22, 2011.

PUREZA, José Manuel; Cravo, Teresa. Margem crítica e legitimação nos estudos para a paz. Revista Crítica de Ciências Sociais, Coimbra, Portugal, n. 71, p. 5-19, 2005.

RAMSBOTHAM, Oliver. Reflections on UN PostSettlement Peacebuilding. In: WOODHOUSE; RAMSBOTHAM (Ed.). Peacekeeping and conflict resolution. London: Frank Cass Publishers, 2000. p.169189

RATNER, Steven. The New UN peacekeeping: building peace in lands of conflict after the cold war. New York: St. Martin's Press, 1995.

RENO, William. Warlord Politics in African States. Boulder, Colorado, USA: Lynne Rienner, 1999.

RICHMOND, Oliver. A post-liberal peace: Eirenism and the everyday. Review of International Studies, Cambridge, United Kingdom, v. 35, n.3, p. 557-580, 2009.

RICHMOND, Oliver. De-romanticizing the local, demystifying the international: hybridity in Timor Leste and the Solomon Islands. The Pacific Review, London: Routledge, v.24, n. 1, p.115-136, $2011 \mathrm{~b}$.

RICHMOND, Oliver. Resistance and the post-liberal peace. Millennium: Journal of International Studies, London, United Kingdom, v. 38, n. 3, p. 665-692, 2010.
RICHMOND, Oliver. The problem of peace: Understanding the liberal peace. Conflict, Security \& Development, London, v.6, No.3, p.291-314, 2006.

RICHMOND, Oliver. A post-liberal peace: the local infrapolitics of peacebuilding. London: Routledge, 2011a.

ROBERTS, Adam; KINGSBURY, Benedict (Ed.). United Nations, divided world: the un's roles in international relations. Oxford: Clarendon Press, 1993.

ROBERTS, David. Post-Conflict Peacebuilding, Liberal Irrelevance and the Locus of Legitimacy. International Peacekeeping, London: Routledge, v. 18, n. 4, p. 410-424, 2011.

ROBERTS, David. Saving Liberal Peacebuilding from Itself. Peace Review: A Journal of Social Justice, London: Routledge, v. 24, n. 3, p. 366-373, 2012.

ROBINSON, Piers. The CNN Effect: the myth of news, foreign policy and intervention. London: Routledge, 2002 .

ROTBERG, Robert (Ed.). When States Fail: Causes and Consequences. Princeton, New Jersey, USA: Princeton University Press, 2004.

ROWE, Peter. Maintaining Discipline in United Nations Peace Support Operations: The Legal Quagmire for Military Contingents. Journal of Conflict and Security Law, Oxford, United Kingdom, v. 5, n. 1, p. 45-62, 2000.

SARABATNAM, Meera. Avatars of Eurocentrism in the Critique of the Liberal Peace. Security Dialogue, Oslo, Norway, v. 44, n. 3, p. 259-278, 2013.

SAVE THE CHILDREN. No One to Turn to: the underreporting of child sexual exploitation and abuse by aid and peacekeepers. London: Save the Children Alliance, 2008.

SHAW, Martin. Civil Society and Media in Global Crises: representing distant violence. London: Frances Pinter Publishers, 1996.

SNOW, Donald. Uncivil Wars: international security and the new internal conflicts. Boulder, Colorado, USA: Lynne Rienner Publishers, 1996

SOTO, Alvaro; CASTILLO, Graciana. Obstacles to Peacebuilding. Foreign Policy, Washington D.C., USA, n. 94, p. 69-83, 1994.

SPIRO, David. The Insignificance of the Liberal Peace. International Security, Cambridge, Massachusetts, USA, v.19, n. 2, p.50-86, 1994. 
STEDMAN, Stephen. Spoiler Problems in Peace Processes, International Security, Cambridge, Massachusetts, USA, v. 22 , n. 2, p. 5-53, 1997

STUDIES and World Affairs, Malden, Massachussetts, USA, v. 42, n. 4, p. 39-58, 2000.

TADJBAKHSH, Shahrbanou (Ed.). Rethinking the Liberal Peace: external models and local alternatives. New York: Routledge, 2011.

THEMNÉR, Lotta; WALLENSTEEN, Peter. Armed Conflicts, 1946-2011. Journal of Peace Research, Oslo, Norway, v. 48, n. 4, p. 525-536, 2011.

THOMPSON, William. Democracy and Peace: Putting the Chart before the Horse? International Organization, Cambridge, United Kingdom, v. 50, n. 1, p. 141-174, 1996.

TILLY, Charles. The Politics of Collective Violence. Cambridge: Cambridge University Press, 2003.

UNITED NATIONS. An Agenda For Peace. New York: United Nations, 1992.

UNSG. Special Measures for protection from sexual exploitation and sexual abuse. UNITED NATIONS Secretary General's Bulletin, ST/SGB/2003/13, 2003.
VÄYRYNEN, Tarja. Gender and UN Peace Operations: the confines of modernity. International Peacekeeping, London: Routledge, v. 11, n. 1, p. 125-142, 2004.

VERHOEVEN, Harry. The Self-fulfilling Prophecy of Failed States: Somalia, State Collapse and the Global War on Terror. Journal of Eastern African Studies, London: Routledge, v. 3, n. 3, p. 405-425, 2009.

WALLENSTEEN, Peter; SOLLENBERG, Margareta. Armed Conflict, 1989-2000. Journal of Peace Research, Oslo, Norway, v. 38, n. 5, p. 629-644, 2001.

WEINSTEIN, Jeremy. Mozambique: A Fading U.N. Success Story. Journal of Democracy, Washington D.C., USA, v. 13, n. 1, p. 141-156, 2002.

WEINSTEIN, Jeremy. Inside Rebellion: the politics of insurgent violence. Cambridge: Cambridge University Press, 2007.

YANNIS, Alexandros. State Collapse and its Implications for Peace-Building and Reconstruction. Development and Change, Rotterdam, Netherlands, v. 33, n. 5, p. 817-835, 2002.

ZARTMAN, William (Ed.). Collapsed States: the disintegration and restoration of legitimate authority. Boulder, Colorado, USA: Lynne Rienner Publishers, 1995. 


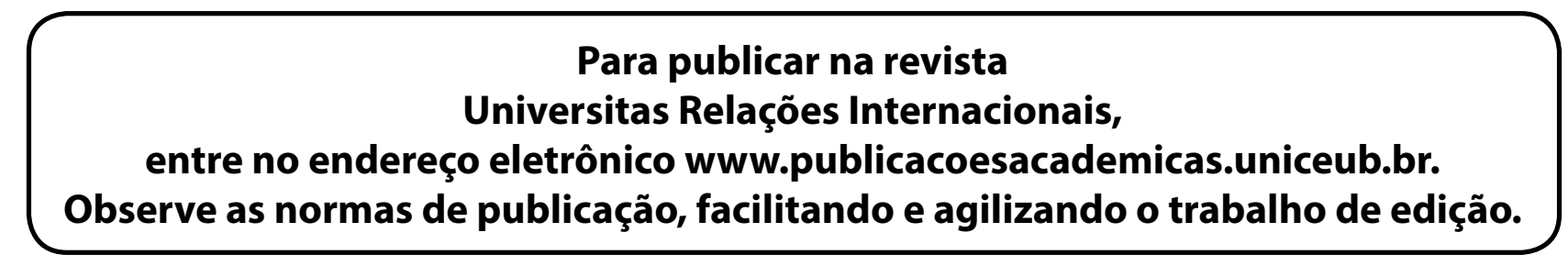

